\title{
Article
}

\section{The NAS-NRC Twin Registry and Duke Twins Study of Memory in Aging: An Update}

\author{
Margaret Gatz ${ }^{1}$, Brenda L. Plassman², Caroline M. Tanner ${ }^{3}$, Samuel M. Goldman², Gary E. Swan ${ }^{5}$, Marianne Chanti- \\ Ketterl $^{2}$, Ellen E. Walters ${ }^{1}$ and David A. Butler 6 \\ ${ }^{1}$ Center for Economic and Social Research, University of Southern California, Los Angeles, California, USA, ${ }^{2}$ Department of Psychiatry \& Behavioral Science, \\ School of Medicine, Duke University, Durham, North Carolina, USA, ${ }^{3}$ Department of Neurology, School of Medicine, University of California, San Francisco, \\ California, USA, ${ }^{4}$ Division of Occupational \& Environmental Medicine, School of Medicine, University of California, San Francisco, California, USA, ${ }^{5}$ Stanford \\ Prevention Research Center, Department of Medicine, Stanford University School of Medicine, Palo Alto, California, USA and ${ }^{6}$ Office of Military and Veterans \\ Health, Health and Medicine Division, The National Academies of Sciences, Engineering, and Medicine, Washington DC, USA
}

\begin{abstract}
The National Academy of Sciences-National Research Council (NAS-NRC) Twin Registry is one of the oldest, national population-based twin registries in the USA. It comprises 15,924 White male twin pairs born in the years 1917-1927 $(N=31.848)$, both of whom served in the armed forces, chiefly during World War II. This article updates activities in this registry since the most recent report in Twin Research and Human Genetics (Page, 2006). Records-based data include information from enlistment charts and Veterans Administration data linkages. There have been three major epidemiologic questionnaires and an education and earnings survey. Separate data collection efforts with the NAS-NRC registry include the National Heart, Lung, and Blood Institute (NHLBI) subsample, the Duke Twins Study of Memory in Aging and a clinically based study of Parkinson's disease. Progress has been made on consolidating the various data holdings of the NAS-NRC Twin Registry. Data that had been available through the National Academy of Sciences are now freely available through National Archive of Computerized Data on Aging (NACDA).
\end{abstract}

Keywords: twins; aged; veterans; dementia; Parkinson's

(Received 24 May 2019; accepted 31 May 2019; First Published online 29 July 2019)

The National Academy of Sciences-National Research Council (NAS-NRC) Twin Registry is a comprehensive registry of White male twin pairs born in the USA between 1917 and 1927, both of the twins having served in the military, largely in World War II (WWII). The registry was created by the Medical Follow-Up Agency (MFUA), established shortly after WWII in response to a request by the US military to the National Academy of Sciences. MFUA personnel, led by Dr. Michael DeBakey, launched the registry in 1958-1959 through obtaining birth certificates for White male multiple births from the years 1917 to 1927 from all states except Arizona, Connecticut, Delaware, Georgia, Maine, Missouri, Utah, Vermont and the city of New Orleans, thus representing $93 \%$ of the US population at that time. Personnel matched birth certificates against Veterans Administration (VA) files to determine veteran status. These efforts led to identifying 15,924 pairs or 31,848 individuals. These 31,848 individual twins constitute the NAS-NRC Twin Registry (Jablon et al., 1967).

As has been described in prior reports in this journal (Page, 2002 , 2006), starting in 1965, the men were mailed a brief questionnaire (Q1) requesting their enrollment in the study and including

Author for correspondence: Margaret Gatz, Email: gatz@usc.edu

Cite this article: Gatz M, Plassman BL, Tanner CM, Goldman SM, Swan GE, ChantiKetterl M, Walters EE, and Butler DA. (2019) The NAS-NRC Twin Registry and Duke Twins Study of Memory in Aging: An Update. Twin Research and Human Genetics 22 . 757-760, https://doi.org/10.1017/thg.2019.45 questions to determine zygosity, with a baseline epidemiological assessment (Q2) mailed after the men replied to Q1. During this period, data were also abstracted for the entire registry from hard copy military records, including branch, rank, dates of entry and separation, information from the induction physical and - for a very small subsample - either Army General Classification or Armed Forces Qualification Test scores. Three subsequent surveys gathered data via mailed questionnaire: a 1974 questionnaire (Q3) focused on education and earnings (Behrman et al., 1980) and epidemiological questionnaires in 1985 (Q7) and 1998 (Q8) that repeated and expanded on health questions in Q2. Questionnaire data were supplemented with medical records and disability data from the VA, beginning with the years during which the man served and continuing through 1985, with the latest death update in 2012. A 2015 list of publications using NAS-NRC Twin Registry data includes 377 entries.

A number of separate data collection efforts engaged twins in the NAS-NRC Twin Registry from its beginnings. In 1969-1972, funded by the National Heart, Lung, and Blood Institute (NHLBI), 514 twin pairs from the registry were recruited for clinical examination by virtue of living near Indianapolis IN, Framingham MA, San Francisco, Davis, or Los Angeles CA. These pairs, known as the NHLBI Twin Study (Feinleib et al., 1977), participated in up to six assessments, the most recent in 2002-2003. Because the evaluations were in-person, they included

(c) The Author(s) 2019. 
Table 1. Sample sizes, age range and zygosity

\begin{tabular}{|c|c|c|c|c|c|}
\hline & Total Registry (at induction) & Baseline $(\mathrm{Q} 2)^{\mathrm{b}}$ & Q3 & Q7 & Q8 \\
\hline Number of respondents & $N=31,848$ & $N=14,299$ & $N=4,938$ & $N=9,475$ & $N=6,247$ \\
\hline Age range & $15-33$ years & $40-56$ years & $47-57$ years & $57-70$ years & $69-82$ years \\
\hline MZ & $37.5 \%$ & $44.2 \%$ & $53.3 \%$ & $45.5 \%$ & $46.9 \%$ \\
\hline $\mathrm{DZ}$ & $47.6 \%$ & $52.5 \%$ & $472 . \%$ & $49.5 \%$ & $47.1 \%$ \\
\hline
\end{tabular}

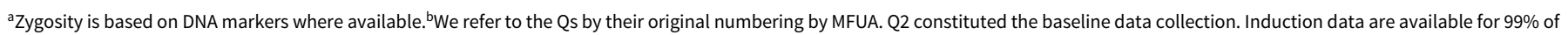
all twins, whether or not they responded to any questionnaire or telephone data collection. Ns show how many men answered each wave.

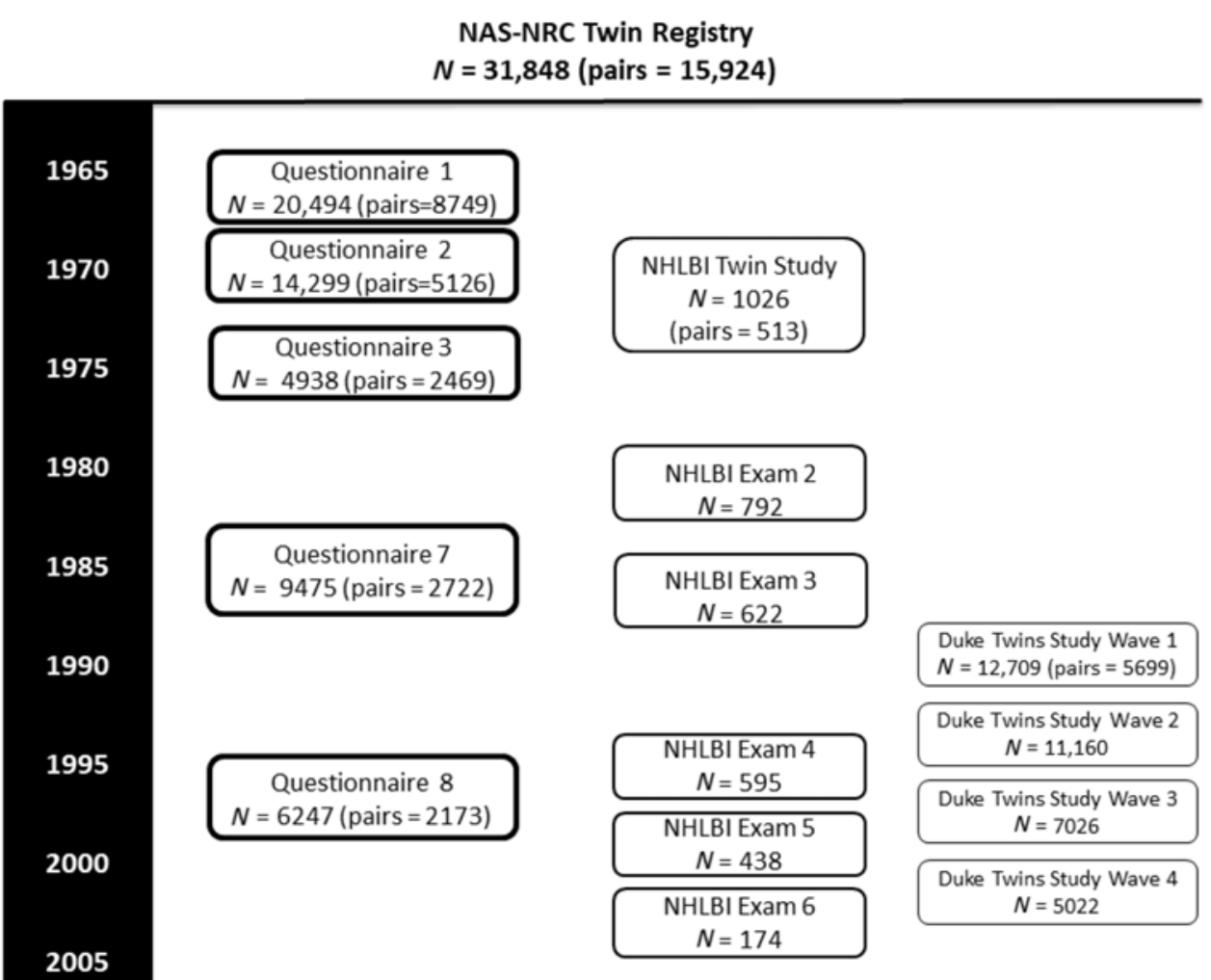

Fig. 1. NAS-NRC study timeline.

cognitive testing, blood samples and three waves of structural neuroimaging.

The Duke Twins Study sample, described by Plassman et al. (2006), comprised all NAS-NRC Registry twin pairs in which both twins were determined to be alive and residing in the USA in 1989. For this purpose, Duke University investigators devoted considerable time to locating twins and updating contact information and vital statistics. There were four waves of data collection, each wave entailing multiple steps: the Telephone Interview for Cognitive Status, modified for epidemiological studies (TICS-m; Plassman et al., 1994) screened for cognitive impairment, with a proxy interview for those who could not complete a telephone interview. At each assessment wave, for individuals scoring below a cut-off on either TICS-m or the proxy interview, an informant was interviewed with the Dementia Questionnaire (DQ; Kawas et al., 1994) to determine whether to proceed to an in-person dementia evaluation. In-person assessments entailed comprehensive clinical evaluations, with the assembled information used to assign a consensus diagnosis as demented, cognitively impaired not demented or cognitively normal; to apply standard criteria for Alzheimer's disease (AD; McKhann et al., 1984) and other types of dementia; and to assign an age of onset for dementia.

The second telephone interview of all individual twins alive in 1992 included screening not only for dementia, but also for suspected Parkinsonism (Tanner et al., 1999). Parkinsonism screening was repeated at the third wave of telephone interviewing from 1996 to 1998. Those who screened positive and their twin brothers were invited to a study of Parkinson's disease (PD). Case ascertainment included an in-person neurological evaluation and a consensus diagnosis. Individuals were followed for a diagnosis of Parkinsonism through 2015 using death certificates (Goldman et al., 2019).

The timeline for data collection and sample sizes are shown in Figure 1. Age ranges and zygosity are shown in Table 1. Note that 
all 15,924 pairs are shown in the table and figure, although some men never responded to any questionnaire or telephone invitation.

Classification of zygosity in Q1 relied on responses to two questions: (1) 'As children were you and your twin as alike as two peas in a pod or of only ordinary family resemblance?'; and (2) 'In childhood, did parents, brothers and sisters or teachers have trouble in telling you apart?' Agreement was 95\% between questionnaire zygosity classification and blood typing results for 741 twin pairs (Hrubec \& Neel, 1978). After DNA genotyping became available from twins seen in person, investigators found $96.8 \%$ agreement between DNA markers and questionnaire zygosity classification for 578 pairs (Reed et al., 2005). As DNA was not available in the majority of cases, a secondary classification of zygosity represents the twin pairs' probability of being monozygotic (MZ), based on a logistic regression model that used existing DNA as the gold standard (Wu et al., 2010).

\section{Notable Features of Registry}

The NAS-NRC Twin Registry represents a unique slice of American history. The men in this registry are largely veterans of WWII — termed 'The Greatest Generation' (Brokaw, 1998) to characterize their core values of personal responsibility, duty and overcoming adversity. WWII involved the nation in a way not true of subsequent wars; thus, WWII veterans are representative of the White male population of the USA of that era. Among all US males aged 45-49 years in 1970, 71\% were WWII veterans (Behrman et al., 1980). Also unique to these men was the 'GI Bill' (formally, the Servicemen's Readjustment Act of 1944) that offered veterans tuition and expenses to attend college or vocational school, as well as low-interest home mortgages. The result was to make higher education available to the working class in a way heretofore unattainable. It is estimated that half of all WWII veterans participated in some educational or training program (National WWII Museum, n.d.; U.S. Department of Veterans Affairs, 2013).

\section{Updates Since Prior Reports}

Although previously potential users of NAS-NRC Twin Registry data applied to the Twins Committee at the National Academy of Sciences and were assessed a user fee, NAS-NRC Twin Registry data are now available at no cost through the National Archive of Computerized Data on Aging (NACDA; Gatz \& Butler, 2017). In addition, we have begun taking steps to consolidate the original NAS-NRC Twin Registry data (including military service records and Q1-Q8) with data collections that have taken place separately, especially the Duke Twins Study TICS-m and clinical diagnosis data. The NAS-NRC Twin Registry contributes data to larger consortia, including the CODATwins Project (Silventoinen et al., 2019) and the Consortium on Interplay of Genes and Environment across Multiple Studies (IGEMS; Pedersen et al., 2019). To stimulate data analyses and facilitate collaborations, the Twins Committee prepared a profile of the NAS-NRC cohort (Gatz et al., 2014).

In an example of collaboration across twin registries, Arden et al. (2016) used data from the NAS-NRC Twin Registry, the Swedish Twin Registry and the Danish Twin Registry to study the association between lifespan and intelligence. There was a small but statistically significant association between cognitive scores and age at death. Twin modeling established that the association was largely driven by genetic effects in all three samples. In other words, intelligence and lifespan are associated due to shared genes, potentially representing fundamental genetic fitness or some gene-environment correlation process where intelligence drives behaviors that promote longevity.

Another example of collaboration across twin registries is Amin et al.'s (2015) test of the effects of education on health. The authors included data from three US studies - the NAS-NRC Twin Registry, the Mid-Atlantic Registry and the Minnesota Twin Registry. Using within-MZ twin pair estimators to identify causal relationships, they found small or nonsignificant associations between schooling and adult health. The finding suggests that associations between education and adult health in nongenetically informed studies may reflect unobserved genetic and social confounds.

Other recent publications are based on NAS-NRC twins' data alone. Duke Twins data from four waves of telephone screening were analyzed by McArdle and Plassman (2009). They estimated heritability of episodic memory at the first wave to be $19 \%$ when including age and education as covariates. Longitudinal models found both additive genetic variance and unique environmental variance to increase with age. The Duke Twins telephone screening at waves 3 and 4 included a scale of Health Limitations of Personally Desired Activities (Gurland et al., 2015). Concordances for MZ and dizygotic (DZ) twins on the separate items were quite similar, indicating that health-related limitations were largely influenced by unique environments. Median concordance at wave 3 was .07 for MZ and .08 for DZ. Median concordance at wave 4 was .11 for MZ and .09 for DZ (Gurland et al., 2015). Wu et al. (2014) used Questionnaire 2 data, when the men were aged 45 to 55 years, to study self-reported alcohol use and hangover. They found $50 \%$ heritability for intoxication and 55\% heritability for hangover. Shared environment played a minimal role.

A recent report estimated concordance and heritability for PD in the NAS-NRC Twin Registry using results from in-person neurological evaluations during the 1990s in combination with National Death Index cause of death data through 2015 (Goldman et al., 2019). Among 220 pairs, probandwise concordance for PD was .20 in MZ and .13 in DZ pairs (heritability 27\%). Genetic liability was much higher in pairs in which PD was diagnosed < age 50 in the first affected twin (MZ concordance .75, DZ concordance .20, heritability $83 \%$ ). Notably, concordance among DZ pairs was several-fold higher than has been reported for samesex nontwin siblings, suggesting substantial effects of shared intrauterine or childhood environment in PD etiology.

Other work with the registry is underway including a study on the long-term outcomes of traumatic brain injury, additional collaborative analyses through IGEMS and CODAT, and individual investigators' studies using data accessed through NACDA.

\section{Access to the Registry}

Data are available at https://doi.org/10.3886/ICPSR36234.v5. Researchers are invited to download the 'DS0 Study-Level Files', including the User Guide, which provide an extensive overview of data collection and phenotypes available, as well as the User Agreement, to complete and return to NACDA.

Acknowledgments. Funding for archiving the NAS-NRC Twin Registry data was provided by Grant No. R21 AG039572 from the National Institutes of Health. Assistance from Harriet Crawford and other staff at the National Academy of Sciences was crucial to the archiving task. Funding for the Duke Twins Study was provided by NIH Grant No. R01 AG08549. 


\section{References}

Amin, V., Behrman, J. R., \& Kohler, H.-P. (2015). Schooling has smaller or insignificant effects on adult health in the US than suggested by crosssectional associations: New estimates using relatively large samples of identical twins. Social Science and Medicine, 127, 181-189.

Arden, R., Luciano, M., Deary, I. J., Reynolds, C. A., Pedersen, N. L., Plassman, B. L., \& Visscher, P. M. (2016). The association between intelligence and lifespan is mostly genetic. International Journal of Epidemiology, $45,178-185$.

Behrman, J. R., Hrubec, Z., Taubman, P., \& Wales, T. J. (1980). Socioeconomic success. A study of the effects of genetic endowments, family environment, and schooling. Amsterdam: North-Holland.

Brokaw, T. (1998). The greatest generation. New York, NY: Random House.

Feinleib, M., Garrison, R. J., Fabsitz, R., Christian, J. C., Hrubec, Z., Borhani, N. O., \& Wagner, J. O. (1977). The NHLBI twin study of cardiovascular disease risk factors: methodology and summary of results. American Journal of Epidemiology, 106, 284-295.

Gatz, M., \& Butler, D. (2017). National Academy of Sciences-National Research Council Twin Registry (NAS-NRC Twin Registry), 1958-2013. Ann Arbor, MI: Inter-university Consortium for Political and Social Research.

Gatz, M., Harris, J. R., Kaprio, J., McGue, M., Smith, N. L., Snieder, H., Spiro, III, A., \& Butler, D. A. (2014) Cohort profile: The National Academy of Sciences-National Research Council Twin Registry (NASNRC Twin Registry). International Journal of Epidemiology, 44, 819-825.

Goldman, S. M., Marek, K., Ottman, R., Meng, C, Comyns, K., Chan, P., \& Tanner, C. M. (2019). Concordance for Parkinson's disease in twins: A 20year update. Annals of Neurology, 85, 600-605.

Gurland, B. J., Page, W., Small, B., McArdle, J. J., \& Plassman, B. L. (2015). Heritability of health and aging limitations on personally desired activities. Health Psychology Research, 3, 18-22.

Hrubec, Z., \& Neel, J. V. (1978). The National Academy of Sciences-National Research Council Twin Registry: Ten years of operation. In W. E. Nance (Ed.). Twin research: Biology and epidemiology (pp. 189-195). New York, NY: Alan R Liss.

Jablon, S., Neel, J.V., Gershowitz, H., \& Atkinson, G. R. (1967). The NASNRC Twin Panel: methods of construction of the panel, zygosity diagnosis, and proposed use. American Journal of Human Genetics, 19, 33-61.

Kawas, C., Segal, J., Stewart, W. F., Corrada, M., \& Thal, L. J. (1994). A validation study of the dementia questionnaire. Archives of Neurology, 51, 901-906.

McArdle, J. J. \& Plassman, B. L. (2009). A biometric latent curve analysis of memory decline in older men of the NAS-NRC Twin Registry. Behavior Genetics, 39, 472-495.

McKhann, G., Drachman, D., Folstein, M., Katzman, R., Price, D., \& Stadlan, E. M. (1984). Clinical diagnosis of Alzheimer's disease: Report of the NINCDS/ADRDA Work Group under the auspices of the Department of Health and Human Services Task force on Alzheimer's disease. Neurology, 34, 939-944.

National WWII Museum. [n.d]. The GI Bill. Retrieved March 30, 2019, from https://www.nationalww2museum.org/students-teachers/student-resources/ research-starters/research-starters-gi-bill

Page, W. F. (2002). The NAS-NRC Twin Registry of WWII military veteran twins. Twin Research, 5, 493-496.

Page, W. F. (2006). Update on the NAS-NRC Twin Registry. Twin Research \& Human Genetics, 9, 985-987.

Pedersen, N. L., Christensen, K., Dahl, A., Finkel, D., Franz, C. E., Gatz, M., \& Reynolds, C. A. (2019). IGEMS: The Consortium on Interplay of Genes and Environment across Multiple Studies. Twin Research \& Human Genetics, 16, 481-489.

Plassman, B. L., Newman, T. T., Welsh, K. A., Helms, M., \& Breitner, J. C. S. (1994). Properties of the Telephone Interview for Cognitive Status. Application in epidemiological and longitudinal studies. Neuropsychiatry, Neuropsychology, and Behavioral Neurology, 7, 235-241.

Plassman, B. L., Steffens, D. C., Burke, J. R., Welsh-Bohmer, K. A., Newman, T. N., Drosdick, D., \& Breitner, J. C. S. (2006). Duke Twins Study of Memory in Aging in the NAS-NRC Twin Registry. Twin Research \& Human Genetics, 9, 950-957.

Reed, T., Plassman, B. L., Tanner, C. M., Dick, D. M., Rinehart, S. A., \& Nichols W. C. (2005). Verification of self-report of zygosity determined via DNA testing in a subset of the NAS-NRC Twin Registry 40 years later. Twin Research \& Human Genetics, 8, 362-367.

Silventoinen, K., Jelenkovic, A., Sund, R., Honda, C., Aaltonen, S., Yokoyama, Y., \& Kaprio, J. (2019). The CODATwins Project: The current status and recent findings of Collaborative project of Development of Anthropometrical measures in Twins. Twin Research \& Human Genetics, $18,348-360$

Tanner, C. M., Ottman, R., Goldman, S. M., Ellenberg, J., Chan, P., Mayeux, R., \& Langston, J. W. (1999). Parkinson disease in twins: An etiologic study. JAMA, 281, 341-346.

U.S. Department of Veterans Affairs (2013, November 21). Education and training. history and timeline. Retrieved March 30, 2019, from https:// www.benefits.va.gov/gibill/history.asp

Wu, S.-H., Guo, Q., Viken, R. J., Reed, T., \& Dai, J. (2014). Heritability of usual alcohol intoxication and hangover in male twins: The NAS-NRC Twin Registry. Alcoholism: Clinical and Experimental Research, 38, 2307-2313.

Wu, T., Page, W. F., \& Snieder, H. (2010). Genetic and environmental influences on blood pressure and body mass index in the NAS-NRC World War II Veteran Twin Registry [Abstract]. Twin Research \& Human Genetics, 13, 293. 